\title{
The Disproportionate Impact of the Pandemic on Women and Caregivers in Academia
}

Makala Skinner

Nicole Betancourt

Christine Wolff-Eisenberg 


\section{ITHAKA S+R}

Ithaka $\mathrm{S}+\mathrm{R}$ provides research and strategic guidance to help the academic and cultural communities serve the public good and navigate economic, demographic, and technological change. Ithaka $\mathrm{S}+\mathrm{R}$ is part of ITHAKA, a not-for-profit organization that works to advance and preserve knowledge and to improve teaching and learning through the use of digital technologies. Artstor, JSTOR, and Portico are also part of ITHAKA.

Copyright 2021 ITHAKA. This work is licensed under a Creative Commons Attribution 4.0 International License. To view a copy of the license, please see https://creativecommons.org/licenses/by/4.0/.

ITHAKA is interested in disseminating this brief as widely as possible. Please contact us with any questions about using the report: research@ithaka.org. 


\section{Mounting evidence}

Evidence is mounting that women in academia have disproportionately been affected by the pandemic. Recent research points to new gender gaps in productivity and publishing, with fewer women publishing articles and manuscripts. ${ }^{1}$ And in addition to these professional challenges, women in academia are also facing unique personal challenges during the pandemic, including balancing childcare and home responsibilities while working towards achieving tenure in an academic pipeline where it is already challenging for women to succeed. ${ }^{2}$

These types of gender disparities have been well-documented outside of academia as well. Some scholars have even taken it upon themselves to start building out bibliographies to capture relevant works. ${ }^{3}$ Women have suffered more job losses than men during the pandemic; as of November 2020, women held 5.3 million fewer jobs than they did before the pandemic began in February, compared with a 4.6 million shortfall for men. ${ }^{4}$ And thousands of women are voluntarily leaving the workforce, 5 likely due at least in part to the lack of childcare options available to women and the additional responsibilities they are taking on within their homes. ${ }^{6}$

Likewise, caregivers-those who have care-giving responsibilities for children or a family member, representing roughly one in five Americans7-have also been affected substantially by the pandemic. ${ }^{8}$ Many have found themselves in new or deepened caregiver roles during the pandemic; according to a recent global survey, those with caregiving responsibilities before the pandemic increased their time on caregiving responsibilities by 7.6 hours per week during the

\footnotetext{
1 Judith Hochstrasser, "Fewer Women Published, and a Threat to Open Access," Horizons, December 3, 2020, https://www.horizons-mag.ch/2020/12/03/fewer-women-published-and-a-threat-to-open-access/; Flaminio Squazzoni, Giangiacomo Bravo, Francisco Grimaldo, Daniel Garcıa-Costa, Mike Farjam, and Bahar Mehmani, "No Tickets for Women in the COVID-19 Race? A Study on Manuscript Submissions and Reviews in 2347 Elsevier Journals During the Pandemic," SSRN Electronic Journal, February 21, 2021, https://papers.ssrn.com/sol3/papers.cfm?abstract id=3712813; Tatyana Deryugina, Olga Shurchkov, and Jenna E. Stearns, "Covid-19 Disruptions Disproportionately Affect Female Academics," NBER Working Paper no. 28360, January 2021, https://www.nber.org/system/files/working papers/w28360/w28360.pdf. Additionally, our colleagues found that "COVID-19 has caused additional challenges for researchers with caregiver and child care responsibilities-most markedly on mothers," as part of their review of the impact of COVID-19 on the research enterprise. See Jane Radecki and Roger Schonfeld, "The Impacts of COVID-19 on the Research Enterprise: A Landscape Review," Ithaka S+R, October 26, 2020, https://doi.org/10.18665/sr.314247.

2 Jillian Kramer, "The Virus Moved Female Faculty to the Brink. Will Universities Help?" The New York Times, October 6, 2020, https://www.nytimes.com/2020/10/06/science/covid-universities-women.html; Renate Ysseldyk, Katharine H. Greenaway, Elena Hassinger, Sarah Zutrauen, Jana Lintz, Maya P. Bhatia, Margaret Frye, Else Starkenburg, and Vera Tai, "A Leak in the Academic Pipeline: Identity and Health Among Postdoctoral Women," Frontiers in Psychology 10 (2019):1297, https://www.ncbi.nlm.nih.gov/pmc/articles/PMC6559120/.

${ }^{3}$ A. Goben and N. Haynes, "Women's Labor and COVID-19," May 4, 2020, https://hedgehoglibrarian.com/womenlaborcovidbib/.

${ }^{4}$ Anneken Tappe, Clare Duffy, and Tal Yellin, "These 5 Charts Show the Pandemic's Devastating Effect on Working Women," CNN, December 17, 2020, https://www.cnn.com/2020/12/17/economy/job-losses-women-pandemic/index.html.

${ }^{5}$ Anneken Tappe, "A Shocking Number of Women Dropped Out of the Workforce Last Month", CNN, October8, 2020, https://www.cnn.com/2020/10/07/economy/women-workforce-coronavirus/index.html.

${ }^{6}$ Anneken Tappe, "Working Mothers Are Quitting to Take Care of their Kids, and the US Job Market May Never be the same", CNN, August 19,2020, https://www.cnn.com/2020/08/19/economy/women-quitting-work-child-care/index.html

${ }^{7}$ AARP and National Alliance for Caregiving, "Caregiving in the United States 2020", AARP, May 2020, https://www.caregiving.org/wp-content/uploads/2020/08/AARP1316 ExecSum CaregivingintheUS 508.pdf.

${ }^{8}$ Please note that throughout this report, we use the term "caregiver" to refer to individuals with substantial caregiving responsibilities for others in their family and/or household. We do not use this term to refer to individuals for whom caregiving is a paid profession or career.
} 
pandemic, and 20 percent of caregivers newly assumed caregiving roles as a direct result of the pandemic. ${ }^{9}$ Within the US specifically, more than two-thirds of caregivers found that caring for someone during the pandemic caused them to feel more burnt out than ever before, and that the pandemic has worsened their emotional and mental health overall. ${ }^{10}$ The demands of caregiving coupled with the impacts of the pandemic are presenting a significant set of challenges.

These stressors also impact caregivers in the workplace. A recent international survey of employed caregivers reported that over half of employees said that their employer hasn't offered support that directly addresses their responsibilities at home during the pandemic. ${ }^{11}$ In another recent survey of women in the workforce, more than one in four with caregiving responsibilities felt their professional development had been stifled during the pandemic. ${ }^{12}$ Most notably, the survey also found that almost one-third of women respondents knew another woman who had recently left the workforce because of caregiving responsibilities. The personal and professional challenges facing women and caregivers, especially in light of the COVID-19 pandemic, are substantial and concerning.

\section{The Ithaka S+R COVID-19 Faculty Survey}

In the fall of 2020, we fielded the Ithaka S+R COVID-19 faculty survey, ${ }^{13}$ a survey designed to help colleges and universities improve their engagement with and support for their faculty members, at a large urban university system of two- and four-year institutions within the US. The survey took respondents roughly 8-10 minutes to complete on average, and we collected a total of 3,210 responses across the system for an aggregate response rate of 21 percent.

Our findings from this project not only reinforce many of the same trends that others are reporting - that women and caregivers are at a huge disadvantage as the pandemic persists-but bring new data to the fore on the particular activities where these gaps exist. Both women and caregivers-and especially women who are caregivers-are struggling with a variety of difficulties related to balancing their personal and professional responsibilities, including performing activities related to teaching and research, when compared with men and noncaregivers. Women and caregivers are especially limited in their time and ability to conduct or publish research, as well as perform different research-related activities. This issue brief serves to outline these disparities in greater detail and highlight where there are opportunities for

\footnotetext{
9 "Embracing Carers ${ }^{\text {TM }}$ Global Study Shows Covid-19 Has Taken a Significant Toll on the Well-Being of Informal Carers," EMD, February 16, 2021, https://www.emdgroup.com/press-releases/2021/feb/us/Embracing-Carers-Global-Study-NA.pdf.

10 "The U.S. Carer Well Being Index: Who Cares for Caregivers? Perspectives on COVID-19," Embracing Carers, November 17, 2020, https://www.embracingcarers.com/content/dam/web/healthcare/corporate/embracingcarers/home/document/United States Carer Well-Being Index Report FINAL 11.17.20.pdf.

${ }^{11}$ Agnes Uhereczky, "Caregivers Have Been Let Down by Employers - There Is Still Time to Act," Forbes, March 15, 2021, https://www.forbes.com/sites/agnesuhereczky/2021/03/15/caregivers-have-been-let-down-by-employersthere-is-still-time-toact/?sh=3c7d731075ce.

12 "Women at Work Research," SHRM, https://www.shrm.org/hr-today/trends-and-forecasting/research-and-surveys/pages/womenat-work-research.aspx.

13 "COVID-19 Faculty Survey FAQs, "Ithaka S+R, https://sr.ithaka.org/our-work/covid-19-faculty-survey-faqs/.
} 
institutions to implement changes in order to address the growing threat to the success of women and caregivers in academia.

Table 1 - Faculty Respondent Profile

\begin{tabular}{|c|c|c|}
\hline Respondents & Frequency & Percentage \\
\hline Women $^{14}$ & 1,628 & $51.3 \%$ \\
\hline Men & 1,304 & $41.1 \%$ \\
\hline Caregivers ${ }^{15}$ & 1,286 & $40.6 \%$ \\
\hline Women caregivers & 698 & $22.1 \%$ \\
\hline Men caregivers & 513 & $16.3 \%$ \\
\hline Non-caregivers & 1,643 & $51.9 \%$ \\
\hline
\end{tabular}

\section{Intersecting personal and professional challenges}

Both women and caregiver faculty participants in our survey were much more likely to experience a variety of difficulties in their personal and professional lives. In particular, women found it more difficult than men to manage their time (53 percent of women to 39 percent of men), to balance family, household, and work responsibilities ( 56 percent of women to 44 percent of men), and to manage childcare and/or homeschooling children (65 percent of women to 55 percent of men); (see Figure 1). The average gap between men and women was smaller for faculty in the arts and humanities than faculty in the sciences and social sciences. ${ }^{16}$ For example, the gender gap in regards to balancing family, household, and work responsibilities was only four percentage points for faculty in the arts and humanities compared with a 12 percentage point gap in the sciences and a 17 percentage point gap in the social sciences. This was also the case for caregivers, who were significantly more likely than non-caregivers to find difficulty with each of these activities. In addition, nearly one in two (45 percent) caregivers said finding a quiet space for completing their work was difficult, while less than one in five (17 percent) noncaregivers said the same.

It is also worth noting the differences that emerge at the intersection of gender and caregiving. Women caregivers experienced difficulties with time management (63 percent) and balancing family, household, and work responsibilities (75 percent) to a higher degree than men caregivers (48 percent and 61 percent respectively). Women caregivers (41 percent) were also more likely

\footnotetext{
${ }^{14}$ Question: "With which gender(s) do you most identify? Please select all that apply." Respondents who selected "Non-binary," "Another option not listed here (please specify)," and "I prefer not to answer this question" were excluded from analysis due to insufficient numbers.

${ }^{15}$ Question: "Do you have substantial care-giving responsibilities for other people in your household (e.g. parents or children)?” Respondents who selected "I prefer not to answer this question" were excluded from analysis.

${ }^{16}$ Question: "Which of the following best describe(s) or include(s) your field or discipline? Please select all that apply." For comparison between disciplines we combined faculty responses into the following high-level categories: Arts/Humanities, Sciences (includes Agriculture and Natural Resources, Architecture and Engineering, Mathematics and Computer Science, Biological Sciences, and Physical Sciences) and Social Sciences (includes Social Sciences, Education, and Business).
} 
to find working remotely difficult compared with men caregivers (30 percent). This signals that there is an imbalance in the amount of labor that caregivers are engaged in by gender.

\section{Figure 1: How easy or difficult are each of the following for you this semester or term?}

Of those respondents who participated in each activity, the percentage who selected "somewhat difficult" or "very difficult" for each response option, by gender.

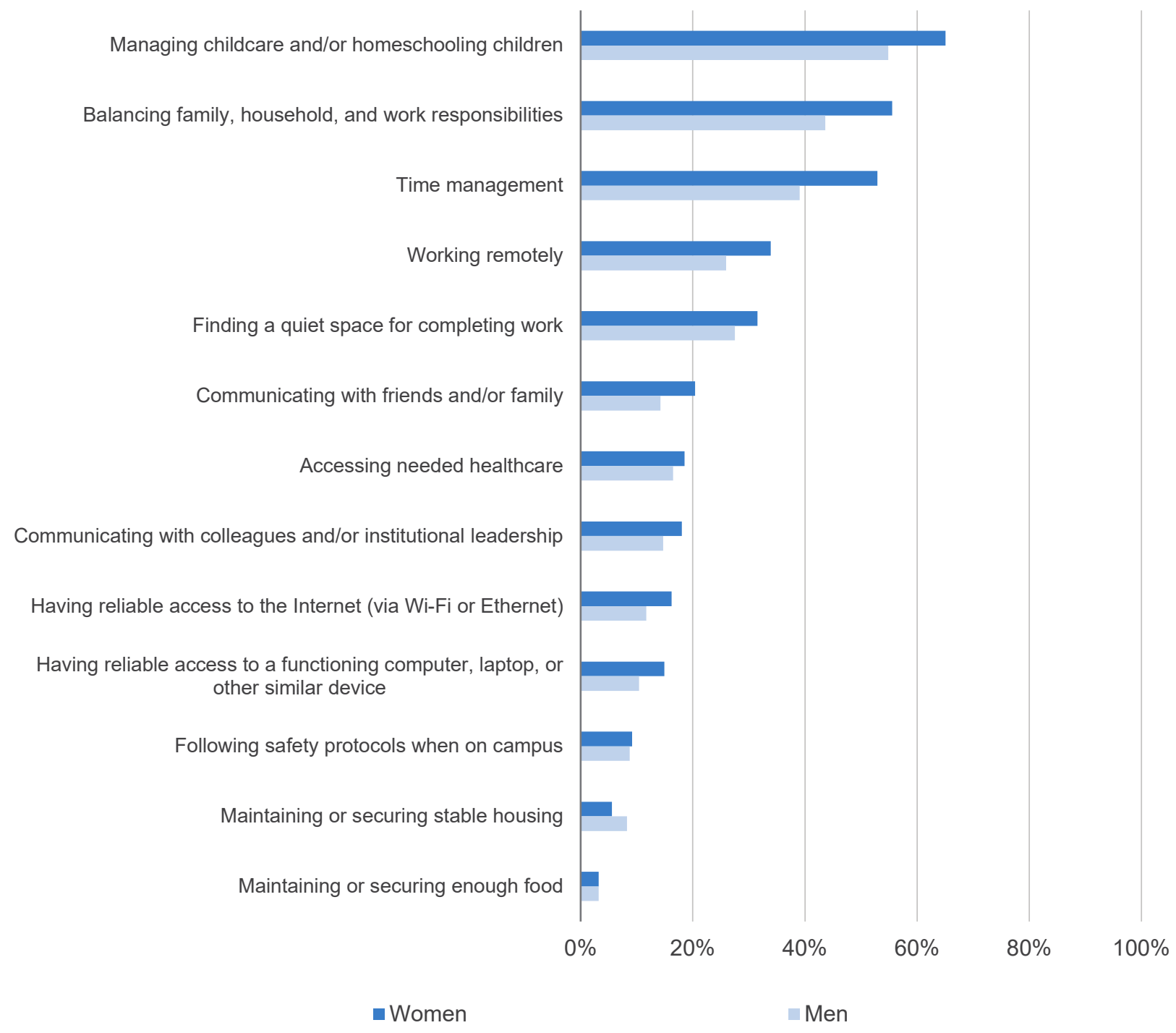

\section{Teaching remotely}

Despite the challenges that faculty have been facing during the pandemic, 86 percent overallwith no substantial subgroup differences-reported at least feeling either somewhat, very, or extremely prepared to teach remotely at the beginning of the fall semester. When asked about preparedness to teach remotely in the future, faculty felt even more positively, with 96 percent indicating that they felt somewhat, very, or extremely prepared. Again, this held true across all 
genders and caregiving statuses. This outcome is one that we have seen consistently over the last several months, with faculty generally indicating that they feel more and more prepared to teach remotely.

However, both women faculty and faculty with caregiving responsibilities did experience somewhat more difficulty with tasks related to teaching than men and non-caregivers. Women found it somewhat more difficult to answer emails from students related to non-academic supports (29 percent women to 20 percent men), such as questions about general wellness, financial aid, and academic or career advising; the same was true for caregivers (31 percent) compared with non-caregivers (22 percent). This gap remained when comparing women caregivers to men caregivers (see Figure 2). Notably, the gender gap in difficulty for teaching tasks was approximately the same regardless of whether faculty work in the sciences, arts and humanities, or social sciences.

Additionally, there was a seven percentage point gap between caregivers and non-caregivers in regards to answering student emails about coursework. This further strengthens the argument that women and caregivers are facing an imbalance in the amount of labor that they are engaged in within their personal and professional lives, which could be contributing to the difficulties that they experienced with performing various activities related to teaching during the fall 2020 semester. 


\section{Figure 2: How easy or difficult is it for you to perform the following activities this semester or term?}

Of those respondents who participated in each activity, the percentage who selected "somewhat difficult" or "very difficult” for each response option, by gender and caregiver status.

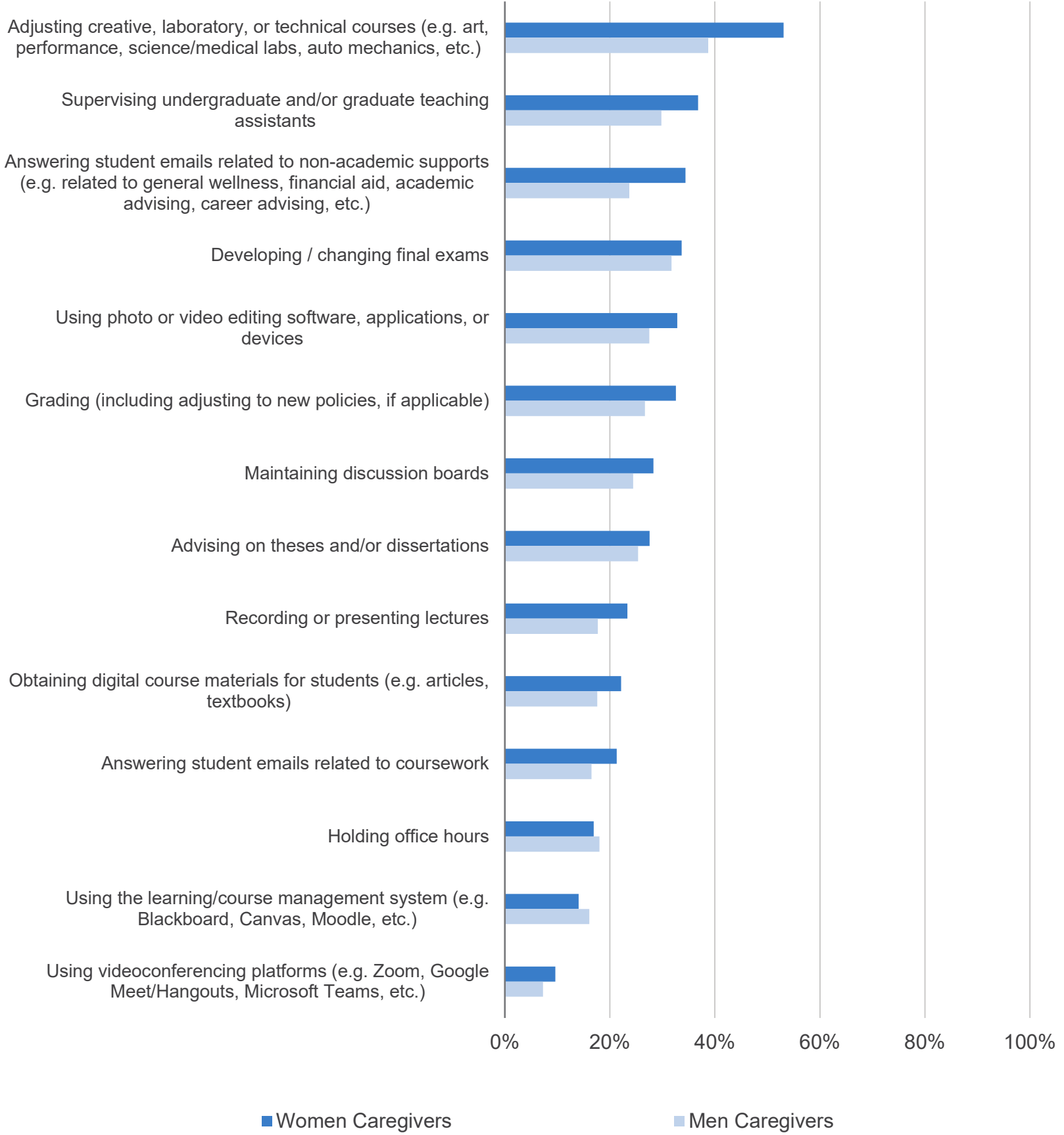




\section{Conducting research at a distance}

While the old adage of "publish or perish" over-simplifies how faculty are assessed and the myriad ways they bring value to an institution and the higher education sector, the phrase does highlight the importance of faculty research, not just to the college or university, but to the career progression of faculty members themselves. In light of this, it is especially concerning to find disparities in research productivity between men and women faculty. While the majority of faculty, regardless of gender, indicated that they worked much less on research than planned during the fall semester ( 57 percent), there was a 12 percentage point gap between women (62 percent) and men (50 percent). The gender gap between women and men in regards to working on research was nearly the same across discipline, with women working less than planned on research in the social sciences (eight percentage point gap), sciences (seven percentage point gap), and arts and humanities (seven percentage point gap). Even when taking into account whether faculty have substantial care-giving responsibilities for other people in their household, a gender gap remained, with 66 percent of women caregivers reporting that they conducted research much less than planned compared with 56 percent of men caregivers. 


\section{Figure 3: How easy or difficult is it to perform the following research activities this semester or term?}

Of those respondents who participated in each research activity, the percentage who selected "somewhat difficult" or "very difficult" for each response option, by caregiver status.

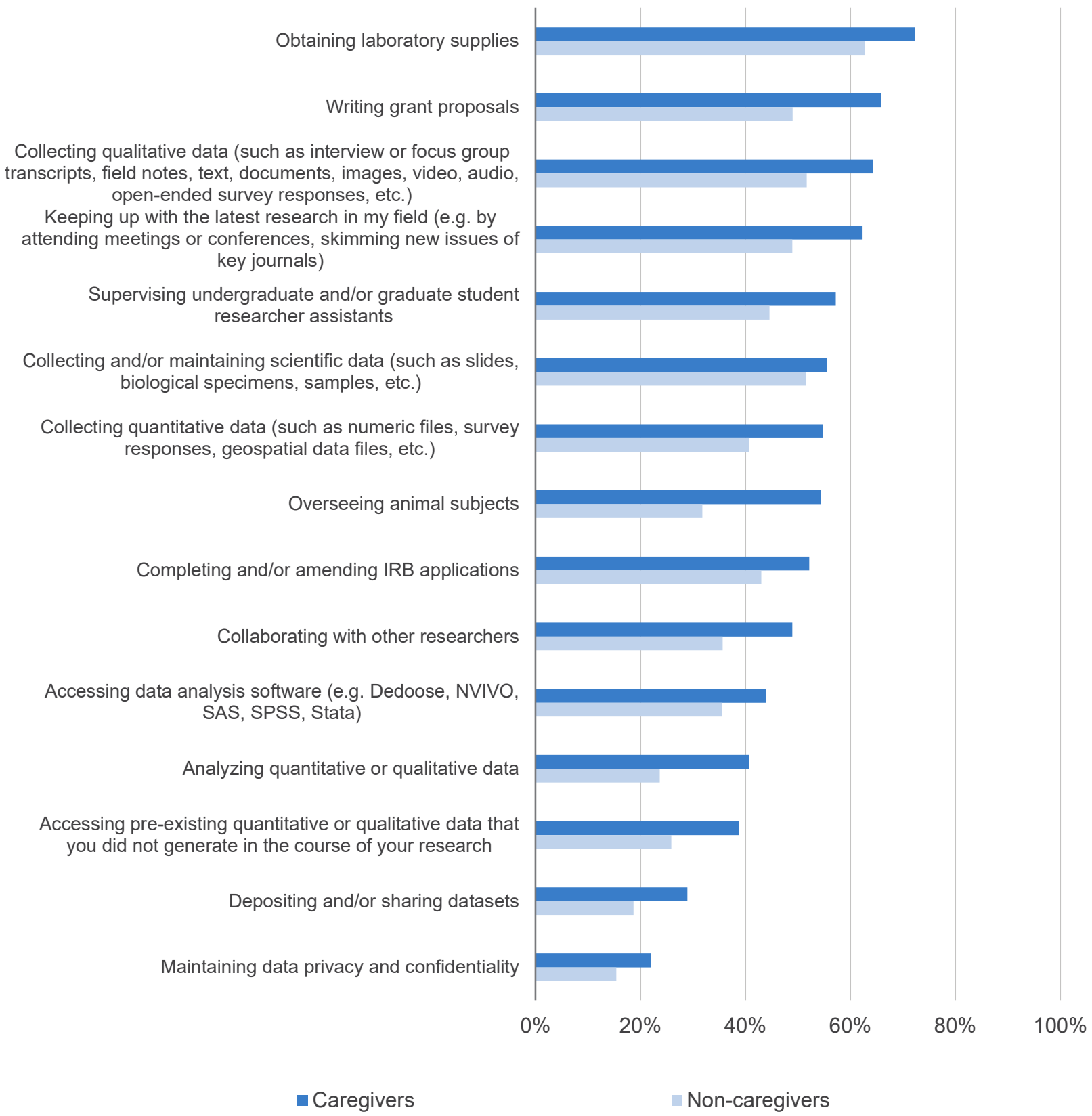

While all faculty found it difficult to perform a variety of research activities during the fall semester-from collecting quantitative and qualitative data to collaborating with other researchers to submitting IRB proposals-women and faculty with caregiving responsibilities 
were particularly impacted, likely due to time constraints. For example, while 24 percent of faculty without caregiving responsibilities found it difficult to analyze quantitative or qualitative data, 41 percent of caregivers felt this way (see Figure 3). Likewise, there was a 17 percentage point gap between caregivers and non-caregivers in how difficult it was to write grant proposals. Strikingly, the average gap between caregivers and non-caregivers was relatively the same across faculty in the sciences, arts and humanities, and social sciences, with no substantial differences across discipline.

A large gap of 15 percentage points also exists between genders in regards to writing grant proposals, with women more likely to say it was difficult. This is particularly alarming given the long-term impact this may have for career advancement in the future.

The largest gaps between men and women in regards to research activities were in the arts and humanities, while social sciences had the smallest average gap. There was a 19 percentage point gender gap for faculty in the arts and humanities in regards to writing grant proposals, while social science faculty only had an eight percentage point gender gap. For collaborating with other researchers, arts and humanities faculty had a 13 percentage point gender gap compared with only a three percentage point gender gap in the social sciences. Gender differences emerged among caregivers as well, with 70 percent of women caregivers finding it difficult to keep up with the latest research in their field compared to 54 percent of men caregivers.

We also saw a decrease in publications and other research outputs among caregivers. Women and those caring for children or other dependents spent less time than usual on research publications compared with men and those without caregiving responsibilities. For example, there was a 15 percentage point gap between caregivers and non-caregivers on a range of research products (see Figure 4). Interestingly, the largest gap between women and men and caregivers and non-caregivers was in the social sciences. In regards to working papers or draft manuscripts, there was a 14 percentage point gender gap for social science faculty compared with a six percentage point gap for science faculty, and a three percentage point gap for arts and humanities faculty. Likewise, the gap between caregivers and non-caregivers is larger for social science faculty (15 percentage points) compared with science faculty (three percentage points) in regards to producing primary source material, including data, images, and media.

Women faculty with caregiving responsibilities bore the brunt of this lost research output. Women caregivers were more likely to spend less time than usual on research outputs compared with men caregivers (see Figure 4). 
Figure 4: Have you worked on each of the following types of research publications and products this past semester or term more, less, or about the same as usual?

Of those respondents who worked on each research publication or product, the percentage who selected "less than usual" for each response option, by gender and caregiver status.

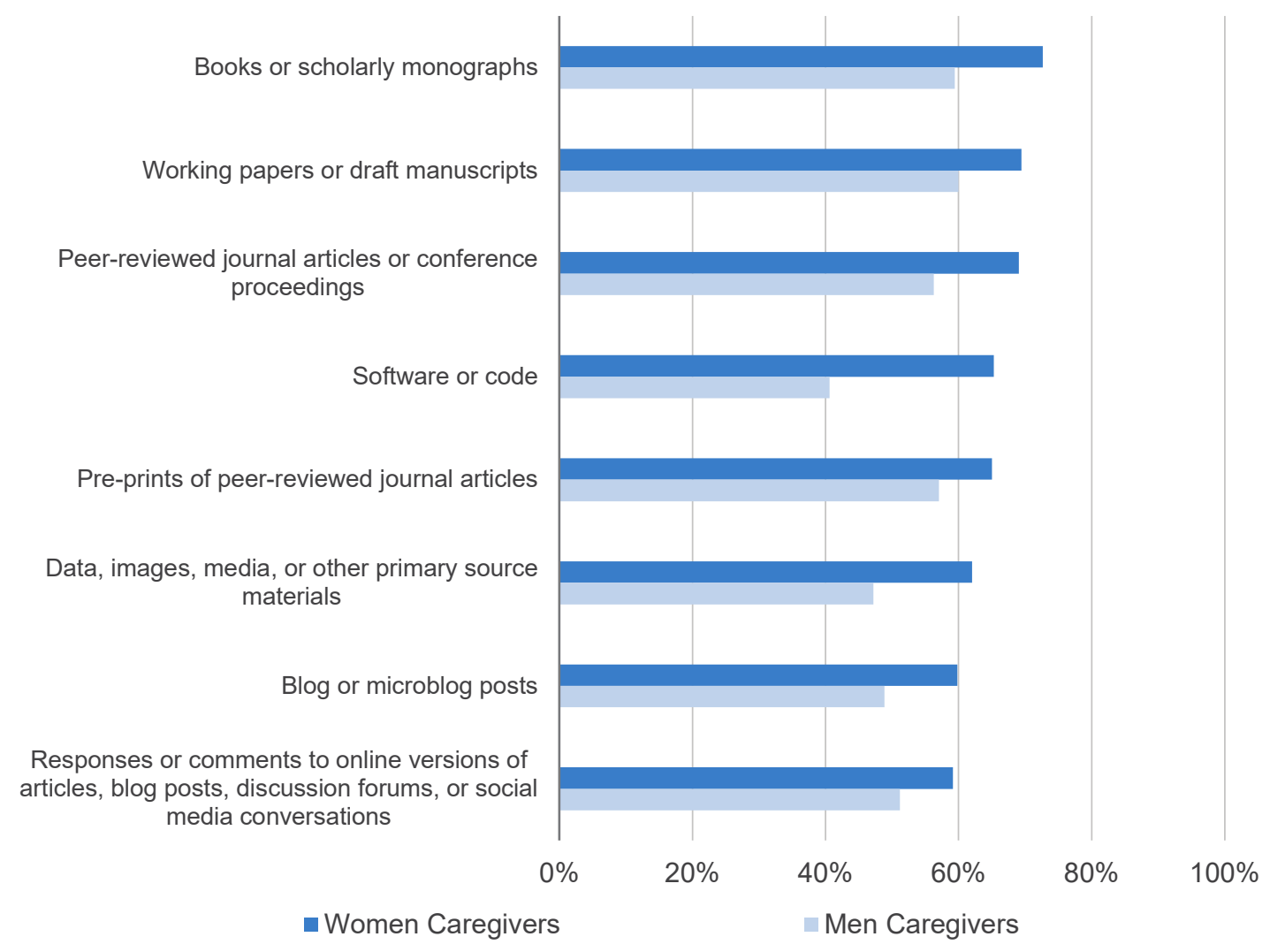




\section{Looking ahead}

The pandemic has undoubtedly affected women in a disproportionate manner. Even when controlling for faculty members' caregiving responsibilities at home, a gender gap remains. We are already one year into the pandemic, and though mass vaccination efforts give us reason to be hopeful that COVID-19's reign is nearing its end, the reverberations of the virus's impact on society writ large-and on those academics working to contribute to it - are likely to be felt for some time.

Our survey findings coupled with the results of so many other studies merit examination of how institutional leaders can mitigate the gender gap in faculty research and support those who have caregiving responsibilities. While there are no easy answers to these questions, institutions thus far have implemented a number of strategies that may hold promise:

- Temporarily reduce or suspend research publication requirements. The National Alliance for Inclusive and Diverse STEM Faculty (ASPIRE) produced a guide, "Supporting Faculty During \& After COVID-19: Don't Let Go of Equity.” 17 ASPIRE recommends that institutions explicitly change research publication expectations for faculty in recognition of the current context. Reducing research requirements in the short-term can help mitigate the inequitable impact of the pandemic.

- Prioritize, simplify, and reduce tasks. Kevin R. McClure, an associate professor at the University of North Carolina at Wilmington, proposes a number of recommendations for supporting burnt out faculty. ${ }^{18}$ In particular, he recommends that institutional leaders think critically about what they ask faculty to take on and what lower-priority tasks can simply be eliminated (temporarily or permanently) from their workload.

- Provide flexibility. ADVANCE at the University of Maryland created a guide for institutional leaders on how to recognize the unequal impact of the pandemic on faculty and help ease this burden. ${ }^{19}$ The guiding principle of the document is flexibility, and it includes several recommendations-postponing major projects where possible, asking faculty for input when designing course schedules, and allowing faculty to teach the same courses they have in the past rather than create new ones.

- Automatically delay tenure review. This past fall, the University of Massachusetts Amherst, among other institutions, decided to defer review of pre-tenured faculty by one year. ${ }^{20}$ This policy was instituted automatically and does not require faculty to request the deferment, an important detail that removed the burden of opting-in or applying. Instead, the institution allowed those who wished to be reviewed on schedule to opt-in.

\footnotetext{
17 "COVID-19 Resources," Aspire Alliance, https://www.aspirealliance.org/national-change/covid-19-resources.

${ }^{18}$ Kevin McClure, "Burnout Is Coming to Campus. Are College Leaders Ready?” EdSurge, August 14,2020, https://www.edsurge.com/news/2020-08-14-burnout-is-coming-to-campus-are-college-leaders-ready.

${ }^{19}$ Office of Faculty Affairs and ADVANCE, "Supporting Faculty Members through the COVID-19," University of Maryland, October 2020, https://advance.umd.edu/sites/advance.umd.edu/files/UnitHeadGuidance15October2020.pdf.

${ }^{20}$ Ethel L. Mickey, Dessie Clark, and Joya Misra, "Measures to Support Faculty During COVID-19," Inside Higher Ed, September 4 , 2020, https://www.insidehighered.com/advice/2020/09/04/advice-academic-administrators-how-best-support-faculty-duringpandemic-opinion.
} 
Strategies such as these may help alleviate the disproportionate impact of the pandemic on faculty. Most importantly, it is crucial that institutions listen to the women and caregivers they employ. Needs may vary from school to school and from person to person; by listening carefully to what faculty members share, institutions may avoid well-intentioned supports that in reality exacerbate rather than alleviate disparities. A new report from the National Academies of Sciences, Engineering, and Medicine highlights some of the tensions in institutional responses. ${ }^{21}$ For example, while delaying tenure review is helpful to some, it is not helpful to all, and may even cause harm by disrupting career trajectories and delaying financial rewards, though this risk may be mitigated by providing faculty with the option to opt-in to their regularly scheduled tenure review. Furthermore, policies concerning tenure do not help faculty in non-tenure track positions, an important, if self-evident, observation. The report notes that white and Asian women are more likely to be in tenure-track positions whereas "Black, Indigenous, and Latinx women tend to be concentrated in non-tenure track appointments." Solely implementing policy changes that support tenure-track faculty is insufficient if the goal is to support all women and caregivers, and may unintentionally widen the gap between women of different race-ethnicities.

As institutions consider how best to support their faculty, it will be necessary to consider how wide-spread policy changes may impact different groups and to think carefully about intersectionality. The challenges faculty and institutions face are complex and require multifaceted, nuanced strategies if they are to be overcome. It is also important to bear in mind that while the pandemic highlighted and deepened disparities between faculty, it did not create them. Schools will need to reflect on long-standing institutional practices related to hiring and promotion in order to adequately address issues of equity.

\footnotetext{
21 "Emerging Evidence Indicates COVID-19 Pandemic Has Negatively Impacted Women in Academic STEM Fields," National Academies of Sciences, Engineering, and Medicine, March 9,2021, https://www.nationalacademies.org/news/2021/03/emergingevidence-indicates-covid-19-pandemic-has-negatively-impacted-women-in-academic-stemm-fields-endangering-progress-made-inrecent-years.
} 